\title{
水酸化鉄（II）ゲルの酸化における $\alpha-\mathrm{FeOOH}$ の溶解析出過程
}

\author{
佳 藤 孝順・岡 本 祥一*・橋本甲四郎 \\ $\left(\begin{array}{c}\text { 千葉工業大学 工業化学科 } \\ * \text { 長岡技術科学大学 電気系 }\end{array}\right)$

\begin{abstract}
The Formation of $\alpha-\mathrm{FeOOH}$ from $\mathrm{Fe}(\mathrm{OH})_{2}$ Gel by the Dissolution-Precipitation Process
\end{abstract}

\author{
Takayori SATO, Shoichi OKAMOTO* and Koshiro HASHIMOTO \\ Department of Industrial Chemistry, Chiba Institute of Technology \\ 17-1, Tsudanuma 2-chome, Narashino-shi 275 \\ * Department of Electrical Engineering, Technological University of Nagaoka
}

\begin{abstract}
Coarse crystals of $\mathrm{Fe}(\mathrm{OH})_{2}$ were prepared by adding iron (II) sulfate solutions to concentrated sodium hydroxide solutions at around $80^{\circ} \mathrm{C}$. The $\mathrm{Fe}(\mathrm{OH})_{2}$ gel was oxidized at $7^{\circ} \mathrm{C}$ by air bubbling. The oxidation of $\mathrm{Fe}(\mathrm{OH})_{2}$ proceeded by the zeroorder reaction with its rate independent of the size of hexagonal $\mathrm{Fe}(\mathrm{OH})_{2}$ crystals which turned into acicular $\alpha-\mathrm{FeOOH}$ crystals. The rate-determining step of the oxidation may be the dissolution of oxygen into the solution. In the oxidation process of the coarse $\mathrm{Fe}(\mathrm{OH})_{2}$ gels, star-shaped aggregates composed of six $\alpha$ - $\mathrm{FeOOH}$ crystals were formed. Electron-diffraction analysis of the star-shaped aggregates indicated that the six equivalent [100] directions in the hexagonal crystal of $\mathrm{Fe}(\mathrm{OH})_{2}$ coincide with the [010] direction in each of six crystals of orthorhombic $\alpha$ - FeOOH. The oxygen arrangement on the (100) hex planes of $\mathrm{Fe}(\mathrm{OH})_{2}$ is equivalent to that on the (010) orth planes of $\alpha-\mathrm{FeOOH}$. It is concluded that $\mathrm{Fe}(\mathrm{OH})_{2}$ crystals in the solution are oxidized selectively on their (100) planes, followed by epitaxial growth of $\alpha$ - FeOOH.
\end{abstract}

[Received February 17, 1986]

Key-words : Oxidation of ferrous hydroxide, Star-shaped crystal, Goethite, Epitaxy, Dissolution-precipitation reaction

\section{1. 緒 言}

現在の磁気記録媒体の主流は, 針状の形状異方性を有 する $\gamma-\mathrm{Fe}_{2} \mathrm{O}_{3}$ 微粒子である。この $\gamma-\mathrm{Fe}_{2} \mathrm{O}_{3}$ は $\mathrm{Fe}(\mathrm{OH})_{2}$ の懸濁液を酸化することにより得られる針状の $\alpha$ $\mathrm{FeOOH}$ を加熱脱水後, 還元し $\mathrm{Fe}_{3} \mathrm{O}_{4}$ とし更に再酸化し て得られている。この一連の合成過程において, 水溶液 中に分散している $\mathrm{Fe}(\mathrm{OH})_{2}$ 微結晶沈殿の酸化の条件は 非常に微妙でわずかな条件の変動により生成相が異な $\eta, \alpha-\mathrm{FeOOH}$ 以外の酸化物, 含水酸化物に変化するこ とはよく知られている ${ }^{1) \sim 4}$. 最終製品としての針状 $\gamma$ $\mathrm{Fe}_{2} \mathrm{O}_{3}$ 微粒子内部に分布している穴，き裂あるいは表面 の凸凹そして枝分かれないし放射状の集合微粒子の存在 等は磁気的性能を著しく損なう大きな原因となる．粒内 の穴，き裂等の形成は， $\alpha$ - $\mathrm{FeOOH}$ を脱水して $\alpha$ - $\mathrm{Fe}_{2} \mathrm{O}_{3}$ に変える過程で起こるが5 ，枝分かれや放射状の粒組織 は $\alpha$ - $\mathrm{FeOOH}$ の双晶形成が原因である。その除去には $\alpha-\mathrm{FeOOH}$ が析出される $\mathrm{Fe}(\mathrm{OH})_{2}$ 沈殿の酸化過程の監 視が重要である ${ }^{6}$. 以上のように磁気記録媒体として優 れた針状 $\gamma-\mathrm{Fe}_{2} \mathrm{O}_{3}$ 微粒子を得るには, $\mathrm{Fe}(\mathrm{OH})_{2}$ 沈殿の 生成及びその酸化による $\alpha$ - $\mathrm{FeOOH}$ の析出過程に関する 基礎的知見が極めて重要である.

著者らは従来より $\mathrm{Fe}(\mathrm{OH})_{2}$ 沈殿の析出状況そしてそ
の酸化過程, 機構について検討を進めてきた 過程で $\alpha-\mathrm{FeOOH}$ が星形に連結して析出するという珍し い現象を見いだした。その結晶析出過程の解析から $\mathrm{Fe}$ $(\mathrm{OH})_{2} \rightarrow \alpha-\mathrm{FeOOH}$ の反応が溶解析出型 ${ }^{3)}$ であるにもか かわらず, 母結晶と生成結晶の接触面で構造の連続性,

つまりエピタキシーが見られることを認めた。

本報告は, $\mathrm{Fe}^{2+}$ 水溶液から出発して $\alpha$ - $\mathrm{FeOOH}$ が得 られるまでの一連の沈殿生成反応とその酸化反応に関す る基礎的知見の蓄積と機構の解明を目指したものであ る.

\section{2. 実験方法}

内容積 $1 l$ のセパラブル四ツロ丸底フラスコに内容積 $1 l$ のポリエチレン製円筒を反応容器としてセットし, フラスコとの間に加熱又は冷却媒体として水を満たし た．中央の管は水酸化鉄（II）沈殿をかき混ぜるための かくはん羽根付きシャフトを通すためであり, 側管は空 気導入, 排出及び温度測定用である。

鉄（II）塩水溶液は硫酸鉄（II） $\left(\mathrm{FeSO}_{4} \cdot 7 \mathrm{H}_{2} \mathrm{O}\right)$ $12.5 \mathrm{~g}$ を無酸素水 $600 \mathrm{ml}$ に, またカセイソーダ水溶液 はカセイソーダ $36 \mathrm{~g}$ を純水 $200 \mathrm{ml}(4.5 \mathrm{~N})$ にそれぞれ 溶解させて作製した。このカセイソーダ量は中和反応に 
対してかなり過剩であり，沈殿反応完了後の水溶液中の カセイソーダ濃度は約 $1 \mathrm{~N}$ となっている, 水酸化鉄 (II) $\left(\mathrm{Fe}(\mathrm{OH})_{2}\right)$ の沈殿析出に際しては，力セイソーダ水溶 液に鉄塩水溶液を加えた。その場合, 各水溶液は設定し た沈殿析出，熟成の温度にあらかじめ加温あるいは冷却 した。沈殿析出後，その温度に保持し熟成を行った，沈 殿を含む水溶液に空気を吹き込み, $\mathrm{Fe}(\mathrm{OH})_{2}$ を酸化し た。酸化に当たっては液温を $10^{\circ} \mathrm{C}$ 以下に保持し，また 空気の吹き込み速度を高速, 中速及び低速(1640 $\mathrm{ml} / \mathrm{min}, 400 \mathrm{ml} / \mathrm{min}, 50 \mathrm{ml} / \mathrm{min}$ ) に選び酸化反応速度 を変化させた。

酸化による溶液中の $\mathrm{Fe}(\mathrm{OH})_{2}$ の減少量は少量採取し た懸濁液中の沈殿を希塩酸で溶解し，その中の $\mathrm{Fe}^{2+}$ 量 を重ク口ム酸カリ水溶液により滴定することから求め た.

熟成による $\mathrm{Fe}(\mathrm{OH})_{2}$ の比表面積変化の測定は, $\mathrm{Fe}$ $(\mathrm{OH})_{2}$ が空気中で容易に酸化されやすく不安定なため, これをいったん $\mathrm{H}_{2} \mathrm{O}_{2}$ 水で急激に酸化し $\delta \cdot \mathrm{FeOOH}$ とし てから行った。比表面積は試料に対する液体窒素温度で の窒素の吸着量加ら BET 式を用いて求めた。

酸化による沈殿粒子形態の変化過程の観察は䋰濁液の 一部を採取し，前述のように $\mathrm{Fe}(\mathrm{OH})_{2}$ を $\delta$ - $\mathrm{FeOOH}$ と して形状を固定して電子顕微鏡を用いて行った. 酸化生 成物について高分解能電子顕微鏡により電子線回折像及 び格子像を観察した。

\section{3. 結果と考察}

\section{1 水酸化鉄（II）の生成及び熟成}

図 1 は $\mathrm{Fe}(\mathrm{OH})_{2}$ 微粒子の電子顕微鏡写真を示す。図 1 (a) は $\mathrm{Fe}(\mathrm{OH})_{2}$ の沈殿を $80^{\circ} \mathrm{C}$ で析出させ, 同温度 で 1 時間保持し熟成させたもの, 図 1 (b) は $10^{\circ} \mathrm{C}$ 以下 で析出させ同温度で 1 時間保持熟成させたものの粒子形 態を示している。なお，実際に粒子形態観察に用いた武 料は $\mathrm{Fe}(\mathrm{OH})_{2}$ 懸濁液をいったん室温程度に戻し， $\mathrm{H}_{2} \mathrm{O}_{2}$ 水を加えて急速酸化により $\delta$ - $\mathrm{FeOOH}$ としたものであ

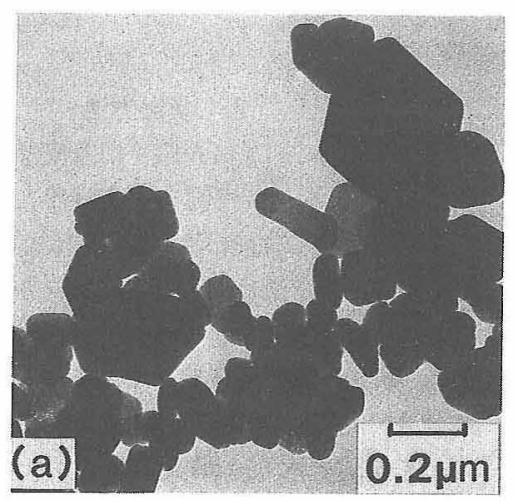

る、この種の酸化反応は典型的なトポタキシー型反応で あり, 酸化前後で微結晶の粒子形態は変化しないことが 確かめられている ${ }^{8}$. 図1(a) 及び（b）に示した粒子 形態の此較から明らかなように, $80^{\circ} \mathrm{C}$ で沈殿析出及び 熟成した $\mathrm{Fe}(\mathrm{OH})_{2}$ の六角板状微結晶は, $10^{\circ} \mathrm{C}$ で析出, 熟成したものに比べて著しく大きい。

図 2 は沈殿析出及び熟成温度を $10^{\circ} \mathrm{C}, 30^{\circ} \mathrm{C}$ 及び $80^{\circ} \mathrm{C}$ に設定した場合の $\mathrm{Fe}(\mathrm{OH})_{2}$ 微結晶の比表面積の時 間依存性つまり，熟成による結晶成長の状況を示したも のである，沈殿析出温度が最も高い $80^{\circ} \mathrm{C}$ (曲線 a) に おいては, 沈殿析出時に大きな結晶が析出し, 熟成によ る成長は顕著でない，これに対し， $10^{\circ} \mathrm{C}$ (曲線 $\left.\mathrm{c}\right)$,

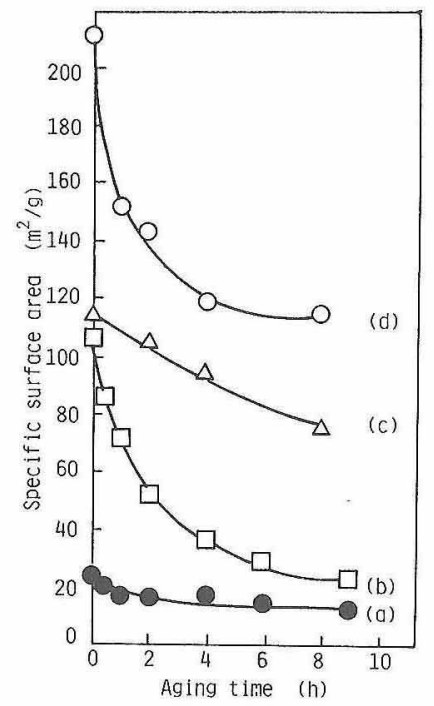

Fig. 2. Elfect of aging on specific surface area of $\mathrm{Fe}(\mathrm{OH})_{2}$ precipitates formed at different conditions.

$\begin{array}{cccc} & \begin{array}{c}\mathrm{Fe}^{2+} \text { soln. } \\ (\mathrm{g} / 600 \mathrm{ml})\end{array} & \begin{array}{c}\mathrm{NaOH} \text { soln. } \\ (\mathrm{g} / 200 \mathrm{ml})\end{array} & \begin{array}{c}\text { Ppted temp. } \\ \left({ }^{\circ} \mathrm{C}\right)\end{array} \\ \mathrm{a}: & 50 & 115 & 80 \\ \mathrm{~b}: & 50 & 115 & 30 \\ \mathrm{c}: & 50 & 115 & 10 \\ \mathrm{~d}: & 50 & 43.2 & 10\end{array}$

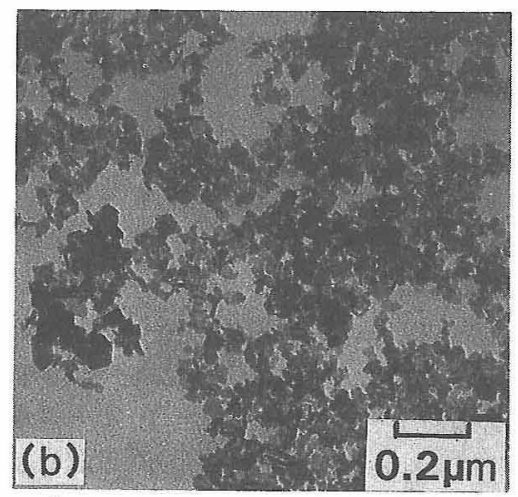

Fig. 1. Comparison of the sizes of hexagonal $\mathrm{Fe}(\mathrm{OH})_{2}$ crystals precipitated at different temperatures. (a) $80^{\circ} \mathrm{C}$, (b) $7^{\circ} \mathrm{C}$ 
$30^{\circ} \mathrm{C}$ (曲線 b) の低温では, 最初に析出する沈殿結晶は 著しく微細であるが, 熟成による結晶成長が顕著である. また，同図中曲線 $\mathrm{d}$ は沈殿生成の際のカセイソーダ濃 度を半減以下にした場合の測定結果である．沈殿析出の 際のカセイソーダ濃度が希薄であると, 微細な $\mathrm{Fe}(\mathrm{OH})_{2}$ の結晶が析出する. 以上のことから, $\mathrm{Fe}(\mathrm{OH})_{2}$ 沈殿微 結晶の大きさは沈殿析出の際の温度とカセイソーダ濃度 とに強く依存し, 沈殿析出の温度が高いと大きな結晶が 得られる. 析出温度が低い場合や，カセイソーダ濃度が 低い場合は, 析出粒子の粒径は小さいが, 顕著な結晶成 長が見られる.

$\mathrm{Fe}(\mathrm{OH})_{2}$ 沈殿を含む強アルカリ性水溶液系では, $\mathrm{Fe}$ $(\mathrm{OH})_{2}$ 微結晶は $\mathrm{Fe}^{2+}$ 錯イオンの拡散層により取り囲ま れていると考えられている ${ }^{2)}$, ．水溶液中に分散してい る微結晶の結晶成長に伴う物質移動は水溶液を通して行 われるので, $\mathrm{Fe}(\mathrm{OH})_{2}$ 微結晶の結晶成長の支配的要因 の一つは $\mathrm{Fe}^{2+}$ イオンの溶解度であると考えられる. 高 温でかつカセイソーダ濃度が高いほど， $\mathrm{Fe}^{2+}$ 錯体の濃 度が高くなり, その結果, 結晶成長が速く進み, 大きな 結晶が得られたと考えられる。

\section{$3.2 \mathrm{Fe}(\mathrm{OH})_{2}$ の酸化による $\alpha-\mathrm{FeOOH}$ 及び $\delta$ -} $\mathrm{FeOOH}$ の生成

図 1 (a) に示した粗大粒子状 $\mathrm{Fe}(\mathrm{OH})_{2}$ を含む水溶液 に空気泡を送り込んで酸化した場合の $\mathrm{Fe}(\mathrm{OH})_{2}$ 沈殿の 含有量の時間変化を図 3 に示す．空気の送り込み速度が 大きいほど $\mathrm{Fe}(\mathrm{OH})_{2}$ は速く酸化され, どの酸化速度の 場合でも, $\mathrm{Fe}^{2+}$ 含有量はほぼ直線的に減少している. つまり，この場合の反応速度はゼロ次式で示される．微 粒子状の $\mathrm{Fe}(\mathrm{OH})_{2}$ 沈殿についても同様な測定を行った が, 測定結果は粗粒子状の場合とほぼ等しい酸化速度で あった.これらのことより, $\mathrm{Fe}(\mathrm{OH})_{2}$ 沈殿の酸化は $\mathrm{Fe}$ $(\mathrm{OH})_{2}$ の粒子の大きさにはあまり関係なく進む.

一方，X線回折による同定の結果から，最終酸化生 成物は酸化前の $\mathrm{Fe}(\mathrm{OH})_{2}$ の結晶の大きさにより異なっ ていることが分かった. すなわち，粗粒子状 $\mathrm{Fe}(\mathrm{OH})_{2}$

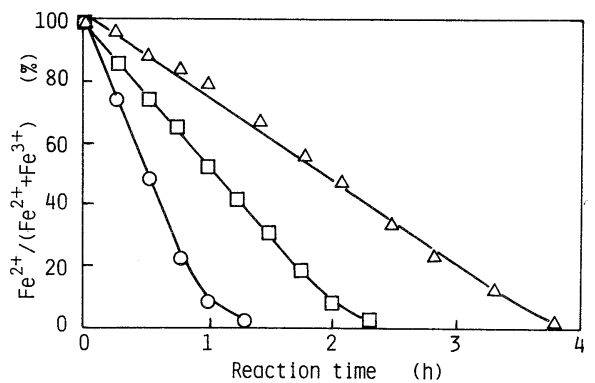

Fig. 3. Linear decrease of $\mathrm{Fe}^{2+}$ during air oxidation of $\mathrm{Fe}(\mathrm{OH})_{2}$ suspension.

Oxidation temperature $: 7^{\circ} \mathrm{C}$

Air bubbling rate : $\bigcirc 1640 \mathrm{ml} / \mathrm{min}, \square 400 \mathrm{ml} / \mathrm{min}$, $\triangle 50 \mathrm{ml} / \mathrm{min}$
沈殿を高速酸化すると, 酸化生成物はほとんど $\delta$ $\mathrm{FeOOH}$ であるが, 酸化速度を中速, 低速とするに伴い $\delta$ - $\mathrm{FeOOH}$ の生成量は減り， $\alpha-\mathrm{FeOOH}$ の生成が優勢と なった。これに対し，微粒子状 $\mathrm{Fe}(\mathrm{OH})_{2}$ を酸化した場 合は，酸化速度に関係なく $\alpha-\mathrm{FeOOH}$ が生成された。 $\mathrm{Fe}(\mathrm{OH})_{2}$ の酸化により $\delta-\mathrm{FeOOH}$ が生成される反応は, $\mathrm{Fe}(\mathrm{OH})_{2}$ 微結晶と水溶液との界面で次式により進 $む^{4), 8)}$.

$$
\begin{aligned}
& \left\langle\mathrm{Fe}^{2+}\right\rangle \rightarrow \quad\left\langle\mathrm{Fe}^{3+}\right\rangle+e^{-} \\
& \left.2<(\mathrm{OH})^{-}\right\rangle \rightarrow \quad\left\langle\mathrm{O}^{2-},(\mathrm{OH})^{-}\right\rangle+\mathrm{H}^{+} \\
& 1 / 4 \mathrm{O}_{2}+e^{-} \rightarrow \quad 1 / 2 \mathrm{O}^{2-} \\
& \mathrm{H}^{+}+1 / 2 \mathrm{O}^{2-} \rightarrow 1 / 2 \mathrm{H}_{2} \mathrm{O} \\
& <\mathrm{Fe}^{2+}(\mathrm{OH})_{2}^{-}>+1 / 4 \mathrm{O}_{2} \rightarrow<\mathrm{Fe}^{3+}, \mathrm{O}^{2-} \text {, } \\
& (\mathrm{OH})^{-}>+1 / 2 \mathrm{H}_{2} \mathrm{O}
\end{aligned}
$$

ここでく >は固体状態にあることを示す.

溶液側から拡散してきた酸素は結晶から電子 $e^{-を も ~}$ らいプロトン $\mathrm{H}^{+}$と結合して水となる。 $e^{-}$と $\mathrm{H}^{+}$とは結 晶内部から表面に供給され, それに伴い固体内部の $\left\langle\mathrm{Fe}^{2+}\right\rangle$ は $<\mathrm{Fe}^{3+}>$ に酸化される。この反応は結晶側 から見れば表面における $\mathrm{H}^{+}$と $e^{-}$との放出であり, 主成 分の鉄イオンや酸素イオンが失なわれるわけではない. それゆえ, 結晶の骨格を構成している酸素イオンの骨格 構造は変わらない.そのため粒子の外形は変わらないし, またこの種の反応がトポタキシー型であるといわれる理 由である。

このように, 粗大粒子状 $\mathrm{Fe}(\mathrm{OH})_{2}$ 沈殿を低温で高速 気泡酸化すると, トポタキシー型反応により $\delta \cdot \mathrm{FeOOH}$ を生ずる，ところが，全く同じ酸化条件で微粒子状 Fe $(\mathrm{OH})_{2}$ 沈殿を酸化すると,この種の反応は全く起こら ず，微粒子の針状 $\alpha$ - $\mathrm{FeOOH}$ に変化する．この反応は粒 形の激変を伴い, 溶解析出型の反応である.

水酸化物の溶解度積は沈殿の結晶化が高くなるにつれ て減少していくといわれている ${ }^{10)}$ 。このことから, 微粒 子状 $\mathrm{Fe}(\mathrm{OH})_{2}$ 結晶を取りまく $\mathrm{Fe}^{2+}$ 錯体の濃度は粗粒子 状 $\mathrm{Fe}(\mathrm{OH})_{2}$ 結晶の場合に比べて高いと考えられる. し たがって微粒子状 $\mathrm{Fe}(\mathrm{OH})_{2}$ 結晶の場合, 溶解酸素が固 液界面の溶液側で $\mathrm{Fe}^{2+}$ 錯体と反応し $\alpha-\mathrm{FeOOH}$ の核発 生に進むと考えられる. つまり, 粗大粒子での酸化は粒 子表面で起こり, 微粒子では固液接触界面の近傍の溶液 側で進む.このように反応の機構が全く異なるにもかか わらず酸化速度はほとんど変わらないこと, 反応速度が ゼロ次であることから, $\mathrm{Fe}(\mathrm{OH})_{2}$ 沈殿の空気酸化の律 速段階は空気中の酸素の水溶液への溶解と考えるのが妥 当であろう。

\section{$3.3 \mathrm{Fe}(\mathrm{OH})_{2}$ と $\alpha-\mathrm{FeOOH}$ との形態の関連}

図 4 (a) 及び (b) は前述の酸化過程を検討している 際, 粗大粒子状 $\mathrm{Fe}(\mathrm{OH})_{2}$ 沈殿をそれぞれ低速又は中速 で気泡酸化した場合に見られた酸化生成物の電子顕微鏡 

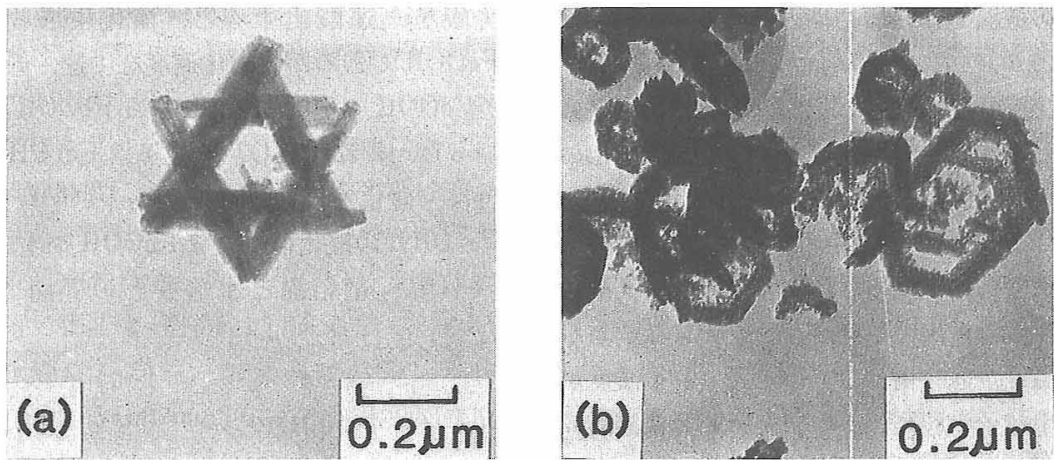

Fig. 4. Particle shape of $\alpha$ - FeOOH aggregates obtained by oxidation of coarse crystals of $\mathrm{Fe}(\mathrm{OH})_{2}$. Conditions of oxidation:

(a) $400 \mathrm{ml} / \mathrm{min}$ at $7^{\circ} \mathrm{C}$, (b) $1000 \mathrm{ml} / \mathrm{min}$ at $7^{\circ} \mathrm{C}$

写真である。同時に得られた電子線回折図形から反応生 成物は $\alpha-\mathrm{FeOOH}$ であること，そして各粒子の長軸方向 は [001] 軸であり，平面上それに直交する軸は [010] 軸であることを確認した.このことは $\alpha-\mathrm{FeOOH}$ が [001] 方向に成長しやすいことと一致する"1. 同図 4 (a) は針 状 $\alpha$ - $\mathrm{FeOOH}$ が星形状に良く発達している例であり, 図 4 (b) は未発達の例を示してある。これら星形状ない し六角状の形態に結晶成長した $\alpha$ - $\mathrm{FeOOH}$ は酸化前の $\mathrm{Fe}(\mathrm{OH})_{2}$ 結晶が図 1 (a) に示すように六角板状である ことから考えて，その形態の影響を強く受けていること は確かである.すなわち, 六角板状 $\mathrm{Fe}(\mathrm{OH})_{2}$ 結晶の六 つの等価な $a$ 面近傍で選択的に酸化が起こり, 同時に $\alpha-\mathrm{FeOOH}$ の核生成，結晶成長に進んだものと解され， 明らかに $c$ 面上では生じていない，そこでこのことを 確認するため, 粗粒子状 $\mathrm{Fe}(\mathrm{OH})_{2}$ 結晶の空気酸化によ る星形状 $\alpha$ - $\mathrm{FeOOH}$ の成長の状沉を調べた。すなわち， 粗粒子状 $\mathrm{Fe}(\mathrm{OH})_{2}$ の酸化途中の䯚濁液を $\mathrm{H}_{2} \mathrm{O}_{2}$ 水で急 激に酸化し，電子顕微鏡で粒子形態を調べたところ，六 角板状 $\mathrm{Fe}(\mathrm{OH})_{2}$ 結晶の $a$ 面に添って針状粒子が生成 し，酸化が進むにしたがって，检状粒子が成長している ことを確認した．このことからも星形状 $\alpha$ - FeOOH は六 角板状 $\mathrm{Fe}(\mathrm{OH})_{2}$ 結晶の $a$ 面に添って生成してできたも のと判断した.

このように溶液系での固相を含む反応においても固体 間反応における場合之同様に反応の生ずる場所，トポス の認識は極めて重要である ${ }^{22}$.

$\mathrm{Fe}(\mathrm{OH})_{2}$ と $\alpha-\mathrm{FeOOH}$ との方位関係を概念的に図 5 に示す. 分かりやすくするため一辺のみを例示した。酸 化前の六方晶 $\mathrm{Fe}(\mathrm{OH})_{2}$ の $[100]_{\mathrm{hex}}$ 方向と酸化後の斜 方晶 $\alpha$ - $\mathrm{FeOOH} の b$ 軸 $[010]_{\text {orth }}$ とが共通していること が分かる。つまり, 前者の $a$ 面上に後者の $b$ 面が発達 した関係となっている.

$\mathrm{Fe}(\mathrm{OH})_{2}$ 結晶の $a$ 面上の $\left(\mathrm{O}^{2-}, \mathrm{OH}^{-}\right)$の配列様式 之 $\alpha-\mathrm{FeOOH}$ の $b$ 面上の $\left(\mathrm{O}^{2-}, \mathrm{OH}^{-}\right)$との関係を図 6

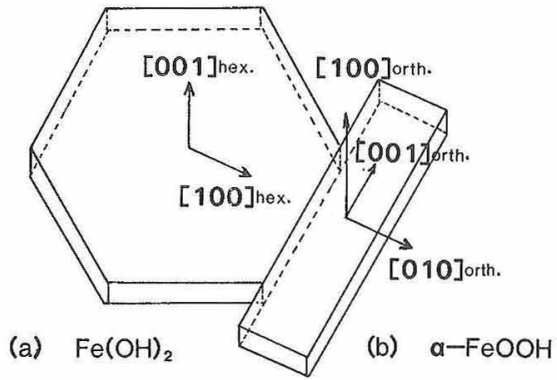

Fig. 5. Correlation in orientation between $\mathrm{Fe}(\mathrm{OH})_{2}$ and $\alpha-\mathrm{FeOOH}$ crystals.

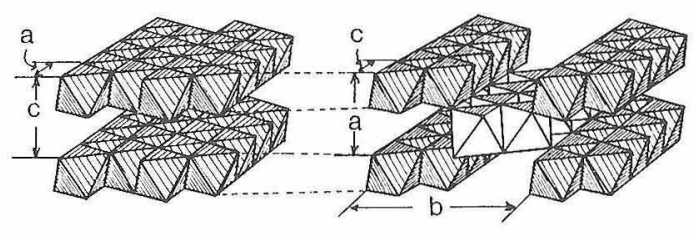

(a) $\mathrm{Fe}(\mathrm{OH})_{2}$

(b) $\quad \mathrm{a}-\mathrm{FeOOH}$

Fig. 6. Continuous arrangements of oxygen between $\mathrm{Fe}(\mathrm{OH})_{2}$ and $\alpha-\mathrm{FeOOH}$

に示す. 両者の酸素イオンの配列様式は同じである12々 14! また, $\mathrm{Fe}(\mathrm{OH})_{2}$ の $a$ 軸の連鎖の方向が $\alpha$ - $\mathrm{FeOOH}$ の $c$ 軸方向に受け継がれていることが分かる.

以上の上うに, $\mathrm{Fe}(\mathrm{OH})_{2} \rightarrow \alpha-\mathrm{FeOOH}$ の変化は明らか に溶解析出型である。それにもかかわらず，これらの間 に構造の連続性が見られる。これは, $\mathrm{Fe}(\mathrm{OH})_{2}$ 結晶の $a$ 面上, 固液界面近傍の溶液側で $\mathrm{Fe}^{2+}$ 錯体が酸化され 凝集して固相よなる際に，エピタキシーにより母結晶 $\mathrm{Fe}(\mathrm{OH})_{2}$ の $a$ 面上の酸素イオンの配列様式を引き継ぐ ものと考えられる. そして六つの等価な $a$ 面上で発生 した $\alpha-\mathrm{FeOOH}$ の核が平等に生成して星形の $\alpha-\mathrm{FeOOH}$ に成長したもの亡解される。 $\alpha \cdot \mathrm{FeOOH}$ が核から結晶へ の成長過程において，鉄イオンの供給源は $\mathrm{Fe}(\mathrm{OH})_{2}$ 結 晶である。図 $4(\mathrm{~b})$ では $\mathrm{Fe}(\mathrm{OH})_{2}$ 結晶の形骸が残り, 
中央付近の物質が失なわれている。このことは，物質移 動そしてそれに伴う電荷移動が $c$ 面上で $a$ 面方向に向 かってだけ起こった結果と解することができる. そして $\alpha$ 面上で酸化され $\alpha-\mathrm{FeOOH}$ 結晶に組み込まれるのであ ろう.

\section{4. 総 括}

(1) $\mathrm{Fe}(\mathrm{OH})_{2}$ 沈殿の析出条件を変えて沈殿微結晶 の形状寸法に対する影響をまず調べた。沈殿温度が高い こと, また析出時のカセイソ一ダ濃度が高いことが Fe $(\mathrm{OH})_{2}$ 微結晶を粗大化する要因であった. 平衡する $\mathrm{Fe}^{2+}$ 錯体の溶解度が強く関係すると考えられた。

(2) $\mathrm{Fe}(\mathrm{OH})_{2}$ 沈殿を含む力七イソーダ水溶液に空 気を送り込み酸化した. 酸化反応速度は被酸化物である $\mathrm{Fe}(\mathrm{OH})_{2}$ 微結晶の寸法の著しい差異にもかからず無関 係であり，しかもその速度式はゼロ次で示されることが 分かった. 酸化反応は溶液への酸素の溶解が律速と判断 された。

(3) 粗大な $\mathrm{Fe}(\mathrm{OH})_{2}$ 結晶を含む沈殿水溶液の酸化 により，星形に集合した $\alpha-\mathrm{FeOOH}$ の析出が見られた。 これは, 六方晶 $\mathrm{Fe}(\mathrm{OH})_{2}$ の六個の等価な $a$ 面上での $\alpha$ $\mathrm{FeOOH}$ の核生成そして成長を考えることにより説明し 得た。

(4) その検討過程で $\mathrm{Fe}(\mathrm{OH})_{2} \rightarrow \alpha$ - $\mathrm{FeOOH}$ の酸化
反応は溶解析出型であるが, $\mathrm{Fe}(\mathrm{OH})_{2}$ の $[100]_{\mathrm{hex}} / / \alpha$ -

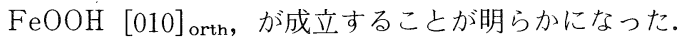
すなわち, $\mathrm{Fe}(\mathrm{OH})_{2}$ の $a$ 面上の酸素配列が $\alpha-\mathrm{FeOOH}$ の $b$ 面へとそのまま引き継がれることが分かった．溶 解析出過程でエピタキシーが起こることを証明した。

謝辞 本稿をまとめるに当たり, 本学工業化学科・宇田 川重和教授並びに長岡技術科学大学・小林健吉郎氏に多大の御 助言を頂いた。ここに記し，深甚なる謝意を表します。

\section{文献}

1) W. Feitknecht, Z. Elektrochem., 63, 34-43 (1959).

2) M. Kiyama, Bull. Chem. Soc. Jpn., 47, 1646-50 (1974).

3) J.D. Bernal, D. R. Dasgupta and A. L. Mackay, Clay Mineral Bull., 4, 15-30 (1959).

4) 岡本祥一, 岡本敞子, 窯協, 85, 518-22 (1977).

5) F. Watari, P. Delavignette, J. Van Landuyt and S. Amelinckx, J. Solid State Chem., 48, 49-64 (1983).

6) Y. Maeda and S. Hirono, Jpn. Appl. Phys., 20, 1991-92 (1981).

7）橋本甲四郎，佐藤孝順，戸田善朝，勲協，86，381-87 (1978).

8) 岡本祥一, 工化, 67, 1845-55 (1964).

9) M. Ehrenfreund and J. Leibenguth, Bull. Soc. Chim. Fr. , 2498-505 (1970).

10）一国雅巳，“無機地球化学”, 培風館 (1978) p. 71-76.

11) G.W. van Oosterhout, Acta Cryst., 13, 932-35 (1960).

12）岡本祥一, 近桂一郎, “マグネトセラミックス”, 技報堂 (1985) p. 214-28

13) M.H. Francombe and H. P. Rooksby, Clay Mineral Bull., 4, 1-14 (1959).

14) S. Okamoto, J. Am. Ceram. Soc., 51, 594-99 (1968). 